\title{
O USO DA LEITURA PARA ENSINAR O CONTEÚDO DE FENÔMENOS NO ENSINO MÉDIO
}

\section{THE USE OF READING TO TEACH THE SUBJECT OF PHENOMENA IN HIGH SCHOOL}

\author{
Roberto Ananias Ribeiro \\ Instituto Federal do Norte de Minas Gerais, Campus Salinas, anan380@hotmail.com \\ Sônia Ribeiro Arrudas \\ Universidade Estadual de Montes Claros/Departamento de Biologia Geral, \\ soniaarruda@yahoo.com.br \\ Ana Paula Venuto Moura \\ Universidade Estadual de Montes Claros/Departamento de Biologia Geral, \\ apvenuto@yahoo.com.br \\ Maria Alice Diniz Martins \\ Universidade Estadual de Montes Claros/Departamento de Biologia Geral, \\ alice.martins@unimontes.br

\section{Maria Orminda Santos Oliveira} \\ Universidade Estadual de Montes Claros/Departamento de Biologia Geral, \\ orminda.oliveira@hotmail.com

\section{Daiane Sousa Dias} \\ Universidade Federal de Minas Gerais/Departamento de Biologia Geral, \\ dasoudias@yahoo.com.br

\section{Karoline Rocha Ribeiro} \\ Universidade Estadual de Montes Claros/Departamento de Biologia Geral, \\ karolealexia@yahoo.com.br

\section{Pedro Fonseca de Vasconselos} \\ Universidade Estadual de Montes Claros/Departamento de Biologia Geral, \\ peuvasconcelos@yahoo.com.br

\section{Izabella Renata Gomes da Cunha} \\ Universidade Estadual de Montes Claros/Departamento de Biologia Geral, \\ bel-belin-ha@hotmail.com
}

\section{Resumo}

A leitura é uma atividade que pode ser usada para o ensino de conteúdos de química. Para ensinar e verificar a compreensão do conteúdo de fenômenos, foi explorado um texto envolvendo a poluição de um rio da cidade Após as aulas dialogadas de Química e de Biologia, foi aplicado um questionário com questões de conhecimento específico sobre fenômenos químico, físico e biológico e conhecimento geral sobre poluição da água e 
tratamento de esgoto em três turmas com alunos do $1^{\circ}$ ano do ensino médio de escolas públicas que são assistidos pelo Núcleo de Atividades para a Promoção da Cidadania da Universidade Estadual de Montes Claros. A identificação dos fenômenos não foi satisfatória, considerando-se os índices de acerto menores que 60,54 e $21 \%$ para os fenômenos químicos, biológicos e físicos, respectivamente, ao contrário da questão sobre poluição da água com índices de acerto maiores que $95 \%$. Sobre o tratamento de esgoto, foram obtidas respostas que demonstraram o conhecimento dos alunos da necessidade dessa medida para a preservação das águas do rio. Foi observada a falta de habilidade dos alunos em fazer a leitura em um nível mais profundo para responder corretamente a questão de conteúdo específico.

Palavras-chave: Leitura. Ensino. Poluição. Química. Fenômenos.

\section{Abstract}

Reading is an activity that can be used to teach subjects of chemistry. Text about river pollution of the city was explored in order to teach and verify the comprehension of the subject of phenomena. After debated Chemistry and Biology classes, questions of specific knowledge about chemical, biological and physical phenomena and general knowledge about water pollution and sewage treatment were applied for students of three first level classes of public high school which are attended by Center of Activity for Citizenship Promotion of the State University of Montes Claros. The phenomena identification was unsatisfactory concerning the level of correct answers lower than 60,54 and $21 \%$ for chemical, biological and physical phenomena, respectively, whereas water pollution question presented level of correct answers higher than 95\%. Good answers were obtained for the sewage treatment question demonstrating that students agree with the necessity this action to preserve the water of river. The students were not able to do the reading of a way deeper to answer the question about specific content correctly.

Keywords: Reading. Teaching. Pollution. Chemistry. Phenomena.

\section{Introdução}

Os programas brasileiros de avaliação como Exame Nacional do Ensino Médio (ENEM), os programas curriculares como os Conteúdos Básicos Comuns (CBC) e o Programa Nacional do Livro Didático (PNDL) preconizam a presença das atividades de leitura em todas as áreas do conhecimento. Tal constatação evidencia a importância da leitura na aprendizagem e que pode contribuir para o domínio dos conteúdos específicos e a formação do cidadão. Ao analisar a matriz de referência do ENEM/2009 (BRASIL, 2009), percebe-se a necessidade da leitura para adquirir as habilidades descritas no documento. Por exemplo, nos eixos cognitivos, item IV, tem-se: "Construir argumentação (CA): relacionar informações, representadas em diferentes formas, e conhecimentos 
disponíveis em situações concretas, para construir argumentação consistente." Como se obtêm informações para relacioná-las e ainda, como construir uma argumentação a partir de uma situação concreta sem a atividade da leitura?

Na Matriz de Referência de Ciências da Natureza e suas Tecnologias, no item Competência de área 7 (Apropriar-se de conhecimentos da química para, em situações problema, interpretar, avaliar ou planejar intervenções científico-tecnológicas), encontramse questões envolvendo meio ambiente e recursos energéticos, as quais demandam o uso de diversas leituras para se alcançar as habilidades pretendidas. O próprio livro didático que muitas vezes é o único acesso de alunos da educação básica à leitura e à cultura letrada (FNDE/2012) é uma fonte de textos sobre as questões citadas anteriormente. Com esse programa, autores de livros didáticos reformularam suas obras a fim de atender às exigências do Ministério da Educação para que os alunos tenham uma formação mais integrada à realidade em que vivem.

$\mathrm{Na}$ proposta curricular do CBC (SEE/MG, 2007), ressalta-se a necessidade da reflexão por parte do professor na sua prática pedagógica ao usar textos, levando-se em conta seus pressupostos teóricos e orientações metodológicas. Para auxiliar o trabalho diário do professor, em termos de metodologia, tem-se o pressuposto "Prover atividades que garantam ao aluno o acesso a diversas fontes de consulta (jornais, revistas, livros paradidáticos, etc.), bem como a pessoas, grupos ou instituições que possam contribuir para o desenvolvimento de valores sociais e culturais." Para executar a leitura, os alunos precisam de materiais diversos e o professor tem de ser um agente ativo nessa etapa para que informações sistematizadas e seguras sejam acessadas por eles.

No estudo da Química, os alunos devem ter a oportunidade de desenvolver habilidades gerais e aprendizagem de conteúdos científicos, como descrito no CBC. No campo da representação e da comunicação, têm-se duas habilidades diretamente relacionadas com a leitura: "Ler textos de diversos gêneros" e "Desenvolver a capacidade de fazer inferências a partir de leitura de textos". Na proposta curricular, sugerem-se temas para projetos que deverão considerar o contexto da escola e o projeto político pedagógico e assim, a leitura torna-se uma ferramenta imprescindível na elaboração desses projetos.

Segundo Geraldi (2011, p. 88), "Leitura é um processo de interlocução entre leitor/autor mediado pelo texto. Encontro com o autor, ausente, que se dá pela sua palavra escrita". Nessa concepção, o leitor assume um papel ativo, estabelecendo um diálogo com o texto, reconstruindo-o a partir da sua maturidade na leitura de outros textos. Na sala de aula, o professor desempenha o papel de testemunha do diálogo entre aluno e autor, pois ele também é um leitor, dando sua significação ao texto lido. Diante do texto, o leitor pode estabelecer diferentes relações de interlocução e uma delas é a busca de informações.

Ao buscar informações, o leitor tem o objetivo de extrair informações. Em textos de Ciências, por exemplo, é mais fácil extrair uma determinada informação, principalmente se for para uma avaliação. A leitura pode ser orientada com e sem roteiro previamente elaborado e ainda pode ser conduzida quanto ao nível de profundidade, superficial ou mais profundo. 
O conteúdo de transformações físicas e químicas, geralmente, é abordado desde o ensino de Ciências, sendo aprofundado no Ensino Médio, na disciplina de Química. Fenômenos físicos são definidos como aqueles em que a composição da matéria é preservada, por exemplo, um ímã que atrai a limalha de ferro e o derretimento do gelo (FONSECA, 2007). Já fenômenos químicos são transformações em que a composição da matéria é alterada, como a queima do papel e o enferrujamento de uma palha de aço.

Um fenômeno biológico pode ser definido como aquela transformação em que a vida esteja envolvida. Segundo os Parâmetros Curriculares Nacionais (Ensino Médio) (PCN, 2000), entre as competências e habilidades a serem desenvolvidas em Biologia, está compreender a vida como um fenômeno biológico que interage com o meio físicoquímico através de um ciclo de matéria e de um fluxo de energia.

A leitura é uma atividade importante, principalmente, no processo de aprendizagem. O simples ato de ler pode ter uma significância muito grande na compreensão daquilo que queremos e precisamos dominar. Alguns trabalhos vêm destacando a importância da leitura na aprendizagem através de pesquisas em que textos, cuidadosamente escolhidos, levam os estudantes a se envolverem nos conteúdos de química dentro de um contexto de "palavras" para depois, num segundo momento, entrarem no formalismo das definições.

Junior (2010) apresenta trabalhos divulgados na literatura brasileira em que a leitura de textos foi relacionada com o ensino de Química. Livros paradidático e infantil, poesia e artigos científicos são materiais utilizados para fazerem uso da leitura ao explorarem os conteúdos. Com esse levantamento bibliográfico, o autor conclui que ainda são poucos os trabalhos desenvolvidos na área e que as pesquisas com o tema leitura vêm crescendo no Brasil. Junior e Júnior (2010) ainda demonstram que a leitura associada à escrita tem um papel importante na exteriorização de dúvidas e aspectos da Ciência que não foram comtemplados somente com a leitura.

A leitura de texto e sua respectiva análise podem ser utilizadas não somente para trabalhar conteúdos, mas também para trabalhar a história da filosofia da ciência como descrito por Moreira (2012) em que o texto teatral envolvendo a descoberta do oxigênio é analisado e a figura do cientista é construída, nos seus aspectos mais humanos, considerando-se a ambição e a busca pelo poder.

Ao fazer uso de um texto em sala de aula, o professor deve escolhê-lo para que seus objetivos sejam alcançados. Se adaptações forem necessárias, assim deve-se fazer para que os resultados sejam positivos. A possibilidade de textos em que aspectos interdisciplinares possam ser explorados torna o material interessante para os alunos. Principalmente no que se referem ao meio ambiente, muitos conteúdos de química podem ser trabalhados a partir de textos encontrados na mídia em geral.

Sendo assim, esse trabalho teve como objetivo fazer um diagnóstico, por meio da leitura de um texto, do conhecimento dos alunos sobre fenômenos físicos, químicos e biológicos, explorando não só as respectivas definições, mas também os aspectos ambientais e sociais envolvidos em um texto. 


\section{Procedimento}

Este trabalho foi realizado no mês de março de 2009, com três turmas do $1^{\text {o }}$ primeiro ano do ensino médio do Núcleo de Atividades para a Promoção da Cidadania (NAP), na Universidade Estadual de Montes Claros (UNIMONTES, 2006).

O NAP é um projeto desenvolvido na Unimontes e tem como objetivo atender às demandas de alunos carentes das escolas públicas da cidade de Montes Claros/MG. O projeto oferece reforço escolar por meio das disciplinas do ensino médio, contribuindo para a transformação da realidade social e cultural da cidade, por meio da complementação educacional ao adolescente, em suas múltiplas relações com a sociedade na qual está inserido. As aulas de reforço escolar são ministradas por acadêmicos da Unimontes e, no caso das aulas de Química, foram os acadêmicos do curso de Biologia que ministraram as aulas em que o trabalho foi desenvolvido.

Após as aulas de Biologia e de Química, abordando os temas Ecologia e Fenômenos Físicos e Químicos, respectivamente, os estudantes das três turmas receberam o texto para leitura, seguido de um questionário com questões objetiva e discursiva para explorar os aspectos conteudistas, sociais e ambientais do tema abordado.

\section{Material}

O texto utilizado descreve uma situação local da cidade de Montes Claros, intitulado "Poluição do Rio Vieira" e é resultado de uma pesquisa realizada por professores e alunos de uma escola estadual (AZEVEDO; MATOS, 2009). O texto é transcrito a seguir.

Quando um rio não tem mais seres vivos vivendo nele, está sujo e malcheiroso e ninguém mais pode usá-lo para o lazer ou para qualquer outra função, diz-se que está poluído. A cidade de Montes Claros conta com uma população de 314 mil pessoas que jogam 530 litros de esgoto por segundo nas águas do Rio Vieira. O rio sofre um fenômeno chamado "eutrofização", ou seja, o despejo de grande quantidade de nutrientes na água, desequilibrando as teias alimentares aquáticas. Esses nutrientes podem estar em forma de matéria orgânica ou na forma de sais minerais. Nessa situação, as bactérias aeróbias se reproduzem de tal forma, que falta oxigênio para elas. A partir daí os micróbios anaeróbios (não usam oxigênio) entram em ação causando o mau cheiro do rio, pois ao realizar a sua digestão, produzem os gases metano, sulfídrico, e ácidos voláteis que poluem o ar com um cheiro nada agradável. Além de toda essa poluição que o rio Vieira sofre, há também a "poluição visual". Quem passa pela avenida não enxerga um rio. O que se vê é uma água nojenta, escura e mal cheirosa, cheia de animais mortos, comprometendo a imagem da nossa cidade. Na periferia, a situação se agrava, uma vez que a precariedade de condições, a falta de saneamento básico, o descaso das autoridades e a falta de informação da população contribuem para o desenvolvimento desse quadro. 
As questões elaboradas foram:

Questão 01: Após a leitura e análise do texto, identifique:

a) um fenômeno químico:

b) um fenômeno físico:

c) um fenômeno biológico:

Questão 02: Com base em seus conhecimentos sobre fenômenos, marque a alternativa CORRETA:

A) O ser humano tem uma relação de muito respeito para com o meio ambiente.

B) Os micróbios anaeróbios contribuem para a despoluição das águas do rio.

C) As águas passam por profundas transformações físicas, químicas e biológicas ao ser poluído.

D) O mau cheiro das águas poluídas é um fenômeno natural que ocorre nesse ecossistema.

Questão 03: Como a implantação da Estação de Tratamento de Esgoto (ETE) pode contribuir para a melhoria da aparência e ecologia do Rio Vieira?

A Questão 01 foi elaborada para verificar o conhecimento do aluno sobre o conteúdo de fenômenos físicos e químicos e ainda foi acrescentado o fenômeno biológico. Na Questão 02, foram avaliadas a compreensão do texto e as informações que se podem inferir a partir dos conhecimentos sobre fenômenos. A Questão 03 envolve uma das soluções possíveis para o problema caracterizado no texto e a partir daí foi verificada a capacidade do aluno em reconhecer as consequências dessa ação no meio ambiente.

\section{Resultados e Discussão}

A escolha de um texto para trabalhar em sala de aula é muito importante. Os alunos podem ter mais facilidade de atribuir uma significação à leitura quando situações do cotidiano são abordadas nos textos e a atividade não passa a ser simplesmente uma simulação de leitura. No presente trabalho, o texto escolhido, além de abordar uma situação real de muitas cidades e inclusive de Montes Claros, possui a característica de ter sido elaborado por alunos do ensino médio assim como os alunos participantes da pesquisa.

Silva (2003) trabalhando nas construções da escrita e da leitura com crianças de 6 e 7 anos de idade, observou que a leitura de textos envolvendo experiências vividas pelas crianças auxiliaram no processo de alfabetização. Esse resultado evidencia que as atividades de leitura devem ser realizadas de forma que os alunos não percebam, de imediato, que estão envolvidos com um conhecimento específico. Com essas características e considerando os resultados da pesquisa citada anteriormente, acredita- 
se que o texto escolhido, neste trabalho, tenha facilitado o acesso às informações nele contidas pelos alunos-leitores. Apesar dele não ter sido criado para a finalidade de um trabalho em sala de aula, foi percebida a presença de transformações as quais puderam ser classificadas em químicas, biológicas e físicas, dentro de um contexto envolvendo a degradação de um rio da cidade.

Foram avaliados 24, 24 e 30 questionários nas turmas 1, 2 e 3, respectivamente. A Figura 1 mostra os resultados da Questão 1. Trata-se de uma questão em que o tema é explorado no ensino fundamental (CASTELI et al., 2006), entendendo-se que os alunos saberiam identificar fenômenos químicos, físicos e biológicos contidos no texto. Assim, exemplos de fenômenos que poderiam ser identificados pelos alunos são: fenômenos químicos- eutrofização, digestão dos micróbios e produção de gases; fenômenos físicoslançamento de lixo no rio, liberação de gases no ar e água contendo animais mortos; fenômenos biológicos- desequilíbrio das teias alimentares, reprodução das bactérias e digestão dos micróbios.

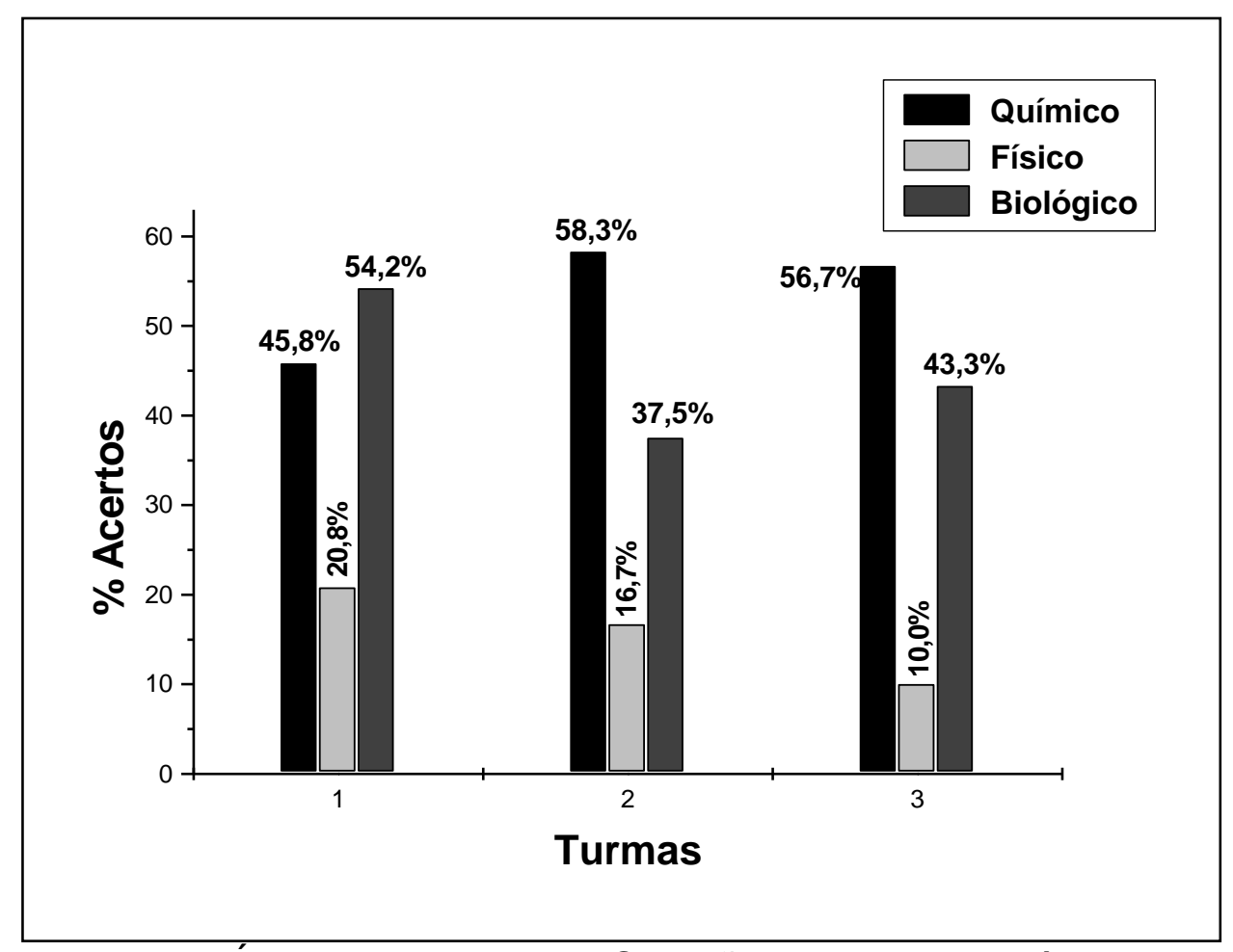

Figura 1- Índice de acertos da Questão 1 dos questionários aplicados.

Os resultados obtidos não foram satisfatórios para as três turmas, principalmente, na identificação de fenômenos físicos. Um maior número de acertos foi observado para a identificação de fenômenos químicos para as turmas 2 e 3 com 58,3 e 56,7\%, respectivamente. Os fenômenos químicos do texto foram apresentados mais explicitamente, ao contrário dos físicos. Em relação aos biológicos, de forma geral, 0 índice de acertos foi intermediário aos outros fenômenos. A Tabela 1 apresenta exemplos de algumas respostas incorretas dadas pelos alunos. Muitos deles identificaram 0 resultado de um fenômeno em vez do fenômeno propriamente dito, por exemplo, água mal cheirosa em vez de produção de gases que causa mau cheiro. Verificou-se também a deficiência na compreensão de fenômeno como um processo, uma transformação, como 
pode ser percebida nas respostas incorretas encontradas: matéria orgânica, esgoto, sais minerais, seres vivos e oxigênio.

A necessidade da leitura para encontrar a resposta à questão pode ter contribuído para esses resultados. Extrair a informação a partir de um texto pode levar os alunos a erros considerando que, na leitura, não foi estabelecida a interlocução, mesmo o texto tendo as características já citadas anteriormente que o levaram a ser usado nessa atividade. Segundo Assunção (2007), a ausência de interlocução na leitura de texto em sala de aula se dá por ser a prática meramente escolar. Os sujeitos envolvidos não buscaram fazer sentido na leitura e, nesse caso, alguns motivos poderiam ter levado os alunos a não interagirem com o texto: a falta de prática de uma leitura crítica e mais aprofundada, o desinteresse pelo assunto, a falta de habilidade do professor em atuar como mediador e até mesmo o não entendimento do conteúdo de fenômenos.

Tabela 1: Respostas incorretas sobre fenômenos químicos, físicos e biológicos dos alunos das três turmas estudadas.

\begin{tabular}{|c|c|}
\hline Fenômenos & Respostas encontradas \\
\hline Químico & $\begin{array}{l}\text { Falta de oxigênio para as bactérias aeróbias; esgoto; matéria } \\
\text { orgânica (Turma 1); } \\
\text { A água nojenta, escura e mal cheirosa; ácidos voláteis (Turma 2); } \\
\text { Esgoto; animais mortos; nutrientes (Turma 3). }\end{array}$ \\
\hline Físico & $\begin{array}{l}\text { Poluição dos rios; os nutrientes podem estar em forma de } \\
\text { matéria orgânica; bactérias (Turma 1); } \\
\text { Sais minerais; eutrofização; poluição visual (Turma 2); } \\
\text { Produção de microorganismos; falta de oxigênio; cadeia } \\
\text { alimentar danificada (turma 3). }\end{array}$ \\
\hline Biológico & $\begin{array}{l}\text { Cheia de animais mortos; seres vivos; oxigênio (Turma 1); } \\
\text { O despejo de grande quantidade de nutrientes na água; poluição } \\
\text { no rio; ácidos voláteis (Turma 2); } \\
\text { Observação do rio; as teias alimentares aquáticas; matéria } \\
\text { orgânica (Turma 3). }\end{array}$ \\
\hline
\end{tabular}

Fonte: Elaborado pelos autores deste trabalho.

Nos resultados da Questão 2, o índice de acertos foi 100, 95,8 e 96,7\% para as turmas 1, 2 e 3, respectivamente. Isso demonstrou que os alunos compreendem que o rio passa por grandes transformações quando se torna poluído, ficando claro esse aspecto no texto apresentado.

As respostas mais encontradas na Questão 3 foram o tratamento do esgoto, a obtenção de água mais clara e sem mau cheiro e despoluição do rio. Duas respostas escolhidas foram transcritas dos questionários e apresentadas a seguir:

"Porque com a implantação da estação de tratamento de esgoto o rio Vieira será despoluído, assim sua aparência melhorará como também o seu ecossistema, com a volta dos seres vivos que nele viviam." 
"Sim. Com a implantação da ETE os esgotos serão tratados antes de serem jogados no rio, assim contribuindo para a melhoria da aparência e ecologia do rio Vieira e de outros rios também."

Nas Questões 2 e 3, ao explorar assuntos relacionados com a vivência deles enquanto inseridos numa sociedade, as respostas foram respondidas, naturalmente, considerando-se o aspecto sócio-cultural. Nessas duas questões, o nível de profundidade exigido na leitura é superficial, ao contrário da Questão 1 em que a leitura tem de ser efetuada num nível mais profundo.

Os resultados mostraram a necessidade da prática de leitura com os alunos do NAP, trabalhando com diferentes gêneros de textos e desenvolvendo a capacidade de inferências a partir dessa leitura.

Deseja-se que os alunos assumam uma postura crítica diante da leitura. A formação do leitor crítico é alcançada no ensino gradualmente, no âmbito escolar, iniciando-se na alfabetização já que a criança tem, naturalmente, predisposição para a crítica (KLEIMAN, 2007). A presença do professor, mediador nessa formação, é necessária para instigar o aluno a inferir situações e opiniões no texto e a compará-las com situações e opiniões vivenciais. Os textos compreendidos fazem parte de nossas vivências e propiciam a leitura crítica de outros textos mais abstratos.

Ao explorar um assunto dentro de um texto sobre uma situação local, como é o caso do Rio Vieira, situado na cidade onde moram os alunos, as possibilidades de discussão vão além do conteúdo a ser ministrado. As questões sociais e as do meio ambiente podem ser inseridas a fim de fazer com que a escola cumpra com o seu dever de formar cidadãos.

A escolha dos textos a serem trabalhados deve ser muito criteriosa e a discussão a ser levantada, muito bem planejada. A deficiência na interpretação dos textos pode prejudicar na aprendizagem dos conteúdos, como pôde ser visto no reconhecimento de fenômeno físico no texto analisado.

\section{Conclusão}

O uso de texto para abordar fenômenos químicos, biológicos e físicos foi uma atividade importante para verificar a compreensão dos alunos do NAP sobre tal conteúdo, apresentando as vantagens de tornar o assunto mais atraente e contextualizado e de incentivar a prática da leitura.

\section{Agradecimentos}

Agradecemos à Universidade Estadual de Montes Claros, à Fundação de Amparo à Pesquisa do Estado de Minas Gerais e ao Prof. João Barbosa (coordenador do NAP). 


\section{Referências}

ASSUNÇÃO, A. L. Sob o regime da produção de sentido: reflexões sobre a produção da leitura. Em: Fonseca, M. N. S. (org.), Ensaios sobre a Leitura 2. Belo Horizonte: PUC Minas, p. 54-71, 2007.

AZEVEDO, M. P.; MATOS, M. L. Leitura da paisagem do Rio Vieira: Poluição. Em: Rio Vieira: Retrato de Esperança, 2009. Disponível em: http://pedagogoseovieira.blogspot.com.br/2009/11/leitura-da-paisagem-do-rio-vieira.html. Acesso em: 31 mar. 2017.

BRASIL. Ministério da Educação - MEC. Matriz de Referência para o Enem 2009. Disponível em: http://portal.mec.gov.br/index.php?option=com_docman\&view=download\&alias=841 matriz-1\&category_slug=documentos-pdf\&Itemid=30192. Acesso em: 22 abr. 2014.

CASTElI, A. P.; MARTINS, C. M. C.; PAULA, H. F.; SANTOS, M. B. L.; LIMA, M. E. C. C.; SILVA, N. S.; JUNIOR, O. A.; CASTRO, R. S.; BRAGA, S. A. M. Proposta Curricular de Ciências do Ensino Fundamental - 6ำ a $9^{\circ}$ Ano. Secretaria de Estado de Educação de Minas $\quad$ Gerais, Disponível em: http://crv.educacao.mg.gov.br/sistema_crv/banco_objetos_crv/\%7BBC26290C-C90B44EF-866A-10C750F63D7B\%7D_livro\%20de\%20ciencias.pdf. Acesso em: 02 mai. 2014.

FONSECA, M. R. M. Química: Química Geral. São Paulo: FTD, 2007.

Fundo Nacional de Desenvolvimento da Educação, FNDE. Guia PNLD 2012 - Ensino Médio. Apresentação. Disponível em: http://www.fnde.gov.br/programas/livrodidatico/guia-do-livro/item/2988-guia-pnld-2012-ensino-m\%C3\%A9dio. Acesso em: 22 abr. 2014.

GERALDI, J. W. Prática da Leitura na Escola. Em: Geraldi, J. W. (org.), O texto na sala de aula, 5a. ed., São Paulo: Ática, p. 88-99, 2011.

JUNIOR, W. E. F. Estratégias de leitura e educação química: que relações? Química Nova na Escola, v. 32, n. 4, p. 220-226, 2010.

JUNIOR, W. E. F.; JÚNIOR, O. G. Leitura em sala de aula: um caso envolvendo o funcionamento da ciência. Química Nova na Escola, v. 32, n. 3, p. 191-199, 2010.

KLEIMAN, A. B. Formando Leitores Críticos. Em: Fonseca, M. N. S. (org.), Ensaios sobre a Leitura 2, Belo Horizonte: PUC Minas, p. 99-122, 2007.

MOREIRA, L. M. Oxigênio: uma abordagem filosófica visando discussões acerca da Educação em Ciências - Parte 1: Poder e Ambição. Educação \& Ciências, Bauru, v. 18, n. 4, p. 803-818, 2012.

Parâmetros Curriculares Nacionais (Ensino Médio) - PCN, Parte III - Ciências da Natureza, Matemática e suas Tecnologias, p. 14-21, 2000. Disponível em: http://portal.mec.gov.br/seb/arquivos/pdf/ciencian.pdf. Acesso em: 02 mai. 2014.

Secretaria do Estado de Minas Gerais - SEE. Centro de Referência Virtual do Professor. Proposta Curricular CBC Química - Ensino Médio, 2007. Disponível em: 
http://crv.educacao.mg.gov.br/sistema_crv/index.aspx?id_projeto=27\&id_objeto=39168\&id pai=38935\&tipo=txg\&n1=\&n2=Proposta\%20Curricular\%20-

\%20CBC\&n3=Ensino\%20M\%E9dio\&n4=Qu\%EDmica\&b=s\&ordem=campo3\&cp=ff9933\&c $\mathrm{b}=\mathrm{mqu}$. Acesso em: 22 abr. 2014.

SILVA, M. A. S. S. Construindo a Leitura e a Escrita, 7ạ. ed., São Paulo: Ática, 2003.

UNIMONTES. Universidade Estadual de Montes Claros, Resolução CEPEX no. 073/2006. Disponível em: http://portal.unimontes.br/index.php?option=com_customproperties\&view=show\&task=sho w\&cp_resolucoes=cepex\&cp_ano=2006\&cp_text_search=073\&submit_search=Pesquisar . Acesso em: 06 mai. 2014.

Submissão: 24/09/2014 Aceite: 27/03/2017 